\title{
Disease prevention without relapse: Processes of change for HPV vaccination
}

\author{
Anne C. Fernandez $z^{1,2^{*}}$, Andrea L. Paiva ${ }^{1,2}$, Jessica M. Lipschitz ${ }^{1,2}$, H. Elsa Larson ${ }^{1,2}$, \\ Nicole R. Amoyal ${ }^{1,2}$, Cerissa L. Blaney ${ }^{1,2}$, Marie A. Sillice ${ }^{1,2}$, Colleen A. Redding ${ }^{1,2}$, \\ James O. Prochaska ${ }^{1,2}$ \\ ${ }^{1}$ Department of Psychology, University of Rhode Island, Kingston, USA; ${ }^{*}$ Corresponding Author: annefernandez@gmail.com \\ ${ }^{2}$ Cancer Prevention Research Center, University of Rhode Island, Kingston, USA
}

Received 8 April 2013; revised 12 May 2013; accepted 21 May 2013

Copyright (C) 2013 Anne C. Fernandez et al. This is an open access article distributed under the Creative Commons Attribution License, which permits unrestricted use, distribution, and reproduction in any medium, provided the original work is properly cited.

\section{ABSTRACT}

Background: Human papillomavirus is the most prevalent sexually transmitted infection in the United States and is associated with $70 \%$ of cervical cancers as well as over $90 \%$ of genital warts. Although the HPV vaccine appears in the US immunization schedule during adolescence, a large percentage of women reach adulthood without being vaccinated. The Transtheoretical Model's (TTM) Processes of Change (POC) construct provides an assessment of participants' experiences with HPV vaccination and is a central component of computer-tailored interventions designed to increase compliance with medical recommendations, such as vaccination. This study describes development and validation of a POC measure for increasing HPV vaccination among young adult women. Methods: Cross-sectional measurement development was conducted using an online survey to reach a sample of $\mathbf{3 4 0}$ female college students representing vaccinated and unvaccinated women. Factor analytic structural equation modeling as well as evaluations of the stage by POC were used to evaluate the validity of the POC measure. Results: Confirmatory analyses supported the theoretically expected ten-factor, fully correlated model as the best fit for the data. Expected Stage of Change to $\mathrm{POC}$ relationships were also confirmed insofar as each POC was significantly associated with Stage of Change, with the exception of dramatic relief. Follow-up analyses suggested that individuals in the Precontemplation stage used all POC less frequently than individuals in all other stages. Conclusions: The POC measure was found to be internally and externally valid in a sample of college-attending women. The POC measure developed may be used to tailor stage-matched interventions that increase use of experiential and behavioral strategies important for increasing HPV vaccination in this high-risk population.

Keywords: Human Papillomavirus;

Transtheoretical Model; Processes of Change; Vaccine

\section{INTRODUCTION}

Human papillomavirus (HPV) is the most common sexually transmitted infection in the United States [1]. High-risk types of HPV (specifically 16 and 18) are associated with $70 \%$ of cervical cancers diagnosed worldwide and low risk-types of HPV, such as types 6 and 11, are associated with $90 \%$ of genital warts cases [2]. It is estimated that $80 \%$ of sexually active females will be exposed to HPV before they reach 50 years of age [3]. Sexually active young women under 25 are at greatest risk for HPV infection and US prevalence of HPV has been shown to be highest among women aged $20-24$ [4-6]. Female college students have been identified as a high-risk population for HPV infection $[7,8]$.

In June 2006, the Food and Drug Administration approved GARDASIL ${ }^{\circledR}$, a highly efficacious quadrivalent vaccine protective against HPV types 6, 11, 16, and 18 [9]. GARDASIL ${ }^{\circledR}$ is a three dose vaccine series administered over six months. The American Committee on Immunization Practices has recommended routine vaccination of girls aged $11-12$ and catches up vaccination of females aged $13-26$ [10]. Routine vaccination of girls before sexual debut optimizes the protective benefit of the vaccine, but vaccinating girls and women older than 
12 years of age may also help to reduce cervical cancer rates [11]. As of 2009, 44\% of girls aged $13-17$ reported receiving at least one dose of the vaccine series and 27\% reported receipt of all three doses [12]. Data describing vaccine uptake levels among women over 17 years of age are limited, but the 2009 National Immunization Survey found $17 \%$ of women aged $19-26$ had received at least one dose of the HPV vaccine series [13]. Low vaccine uptake among college-aged females requires further examination of variables that may influence vaccine acquisition and completion.

One behavior change model particularly well-suited to examining motivation and decision-making related to HPV vaccination is the Transtheoretical Model of Change (TTM). The TTM is an integrative model of behavior change that has been applied to over 48 health behaviors [14]. It is organized around the Stages of Change and uses ten Processes of Change (POC) to represent activities and experiences that are applied when engaging in intentional behavior change $[15,16]$. Stage of Change is comprised of five stages: Precontemplation (not intending to change), Contemplation (considering change), and Preparation (preparing to make a change), Action (actively engaged in behavior change), and Maintenance (sustaining change). Additional TTM constructs include Decisional Balance and Self-efficacy. Decisional Balance reflects the individual's weighing of the pros and cons of changing their behavior [17]. Self-efficacy describes the individual's situation specific confidence that they can sustain their behavior change despite high-risk or tempting situations to relapse to their unhealthy behavior [1820].

The POC represent the functional dimension of the TTM, outlining the experiential and behavioral ways in which people change [16,21,22]. There are ten POC, comprised of covert and overt activities representing two broad correlated experiential and behavioral domains. The experiential POC represent more covert cognitive and affective experiences/activities, and the behavioral POC represent more overt strategies, like substituting healthy alternatives, finding social support, and reorganizing the environment to promote behavior change (see Table 1). Unlike Decisional Balance which shows a high level of consistency across Stage of Change for 48 health behaviors [14], the pattern of POC across behaviors is less clear. In a comparison of 34 studies on smoking cessation, exercise, substance abuse, diet, and psychological problems, Rosen [23] found varying patterns of experiential and behavioral POC across health behaviors, but did not integrate the pattern of POC across all behaviors the way Hall and Rossi [14] did for the patterns of Decisional Balange across Stage of Change. Thus the consistency of POC across health behaviors remains unknown and it is important to conduct model
Table 1. Processes of change.

\begin{tabular}{|c|c|c|c|}
\hline Process Name & Description & Mean & SD \\
\hline \multicolumn{4}{|c|}{ Experiential Processes } \\
\hline $\begin{array}{l}\text { Consciousness } \\
\text { Raising }\end{array}$ & $\begin{array}{l}\text { Efforts by the individual to } \\
\text { gain awareness, gather } \\
\text { information, or get feedback } \\
\text { regarding the target behavior. }\end{array}$ & 11.31 & 3.74 \\
\hline $\begin{array}{l}\text { Dramatic } \\
\text { Relief }\end{array}$ & $\begin{array}{l}\text { Expression and experience of } \\
\text { affect related to the target } \\
\text { behavior (e.g. fear, hope, } \\
\text { empowerment). }\end{array}$ & 12.31 & 4.40 \\
\hline $\begin{array}{l}\text { Environmental } \\
\text { Reevaluation }\end{array}$ & $\begin{array}{l}\text { Consideration of how the } \\
\text { target behavior influences the } \\
\text { physical and social } \\
\text { environment. }\end{array}$ & 11.48 & 4.85 \\
\hline $\begin{array}{l}\text { Self } \\
\text { Reevaluation }\end{array}$ & $\begin{array}{l}\text { Cognitive and emotional } \\
\text { reappraisal of one's values } \\
\text { related to the target behavior. }\end{array}$ & 12.36 & 4.50 \\
\hline $\begin{array}{l}\text { Social } \\
\text { Liberation }\end{array}$ & $\begin{array}{l}\text { Considering the social } \\
\text { climate and norms related to } \\
\text { the target behavior. }\end{array}$ & 12.58 & 4.15 \\
\hline \multicolumn{4}{|c|}{ Behavioral Processes } \\
\hline $\begin{array}{l}\text { Counter } \\
\text { Conditioning }\end{array}$ & $\begin{array}{l}\text { Applying new ways of } \\
\text { thinking and behaving to } \\
\text { promote behavior change. }\end{array}$ & 10.34 & 4.51 \\
\hline $\begin{array}{l}\text { Stimulus } \\
\text { Control }\end{array}$ & $\begin{array}{l}\text { Strategic control of } \\
\text { situations/triggers that may } \\
\text { interfere with or promote } \\
\text { behavior change. }\end{array}$ & 9.32 & 4.32 \\
\hline $\begin{array}{l}\text { Self } \\
\text { Liberation }\end{array}$ & $\begin{array}{l}\text { Commitment to change and } \\
\text { belief in one's ability to } \\
\text { change. }\end{array}$ & 12.5 & 4.32 \\
\hline $\begin{array}{l}\text { Reinforcement } \\
\text { Management }\end{array}$ & $\begin{array}{l}\text { Application of behavioral } \\
\text { contingencies to promote } \\
\text { behavior change. }\end{array}$ & 10.85 & 4.45 \\
\hline $\begin{array}{l}\text { Helping } \\
\text { Relationships }\end{array}$ & $\begin{array}{l}\text { Use and availability of other } \\
\text { people for social and } \\
\text { emotional support while } \\
\text { making a behavioral change. }\end{array}$ & 12.27 & 4.55 \\
\hline
\end{tabular}

testing when applying the TTM to new behaviors.

HPV vaccination is unique relative to other health behaviors because it lacks a traditional behavioral Maintenance stage and requires relatively little overt behavioral effort to reach the Action stage. Maintenance for HPV vaccination is effectively under biological control once the final dose of the vaccine is completed. People who achieve full-vaccination are no longer dependent on POC or relapse-prevention strategies that typically characterize the Maintenance stage. For most behaviors (such as smoking) the decision to act (i.e. quit) can significantly increase the need for behavior controls to keep progressing and prevent relapse. However, one cannot relapse from vaccination, and thus the Action and Maintenance stages are combined for this application of the 
TTM to HPV vaccination. This staging modification has been successfully applied in organ donation research in the past [24,25], but this is the first published application of the Processes of Change to a behavior without a Maintenance stage.

The aim of the current research was to conduct model testing for the TTM POC measure specific to HPV vaccination among young adult women. This research also serves as an important part of the foundation for a future theory-based intervention.

This project is part of a larger program of research that has already developed measures for Stages of Change, Decisional Balance, Self-efficacy, and knowledge related to HPV and HPV vaccination. This study extends this current program of research on HPV vaccination among adult women by 1) developing a POC measure specific to HPV vaccination in young adult women; 2 ) conducting tests of external validation by examining patterns of POC across Stage of Change; and 3) and examining the relationships between the POC measure and other important TTM constructs.

\section{METHODS}

\subsection{Participants}

A sample of 340 female college students (aged 18 to 26) representing a range of HPV vaccination experiences were recruited in the spring and summer of the recruitment year. The modal age of participants was 18 and the median was 19 . The sample was primarily white (76\%). The mean GPA was $3.01(\mathrm{SD}=0.52)$ and the majority of participants lived on campus $(64 \%)$. The majority of participants $(93 \%)$ reported having health insurance. Among these individuals, just over half (59\%) indicated that the HPV vaccine was covered by their insurance company, $2 \%$ indicated it was not, and 39\% indicated that they "did not know." About half of the sample (50.3\%) had received the full HPV vaccine series and were categorized in to the Action/Maintenance Stage. An additional 7.1\% were in the Preparation stage, $11.2 \%$ were in the Contemplation stage, and $31.5 \%$ were in the Precontemplation stage.

All participants were recruited through undergraduate introductory psychology courses, and e-mail list-serves at a mid-sized public university in the northeastern United States. Participants in earlier Stages of Change (pre-Action) were oversampled in order to procure an adequate number of participants in each Stage of Change. Participants were compensated with either class credit or a \$20 gift card to a local business. Surveys were administered online and accessed through a secure website sent to students by e-mail and/or psychology course websites. Participants were required to read the consent form and indicate agreement prior to accessing the survey. Human subject's procedures were approved by the university's institutional review board.

\subsection{Measurement Development Overview}

A three stage process of measurement development was used [26,27]. This procedure included item development and refinement using focus groups and expert reviews followed by structural equation modeling analyses to refine the POC scales and external validation with existing TTM measures [26-28]. As this was an effort to build a POC model for HPV vaccination, Confirmatory Factor Analysis (CFA) using Structural Equation Modeling (SEM) was used as the primary model development analysis. SEM requires that the conceptualizations of a theory's constructs be especially strong, with clearly defined and testable hypotheses as to how the constructs relate to one another. The POC model has been tested numerous times with other health behaviors [22,29-31]. The testing of various models against one another is an additional asset of CFA that is rarely practiced with other statistical techniques, and can further the understanding of how well a data set supports theoretical hypotheses. Ultimately, the retained model should be the one that fits the data best, both conceptually and empirically [28].

\section{Initial Item Development and Refinement}

Initial item development and refinement was based on a review of the literature supplemented with expert consultation, focus groups and cognitive interviews and followed by pilot testing. Three 1.5 -hour focus groups were conducted $(\mathrm{N}=11)$. The primary purpose of these groups was to assess the HPV-related belief and attitudes of students and generate additional item content that may have been lacking in the literature. Once the items were finalized, five one-on-one cognitive interviews were conducted. The primary purpose of these interviews was to determine clarity and readability of the item pool and the instructions sets within the survey. All participants were undergraduate women ages 18 to 26 years old.

\subsection{Measures}

\subsubsection{Stage of Change}

A short series of questions regarding past and present experience with the HPV vaccination was administered [32]. These questions were designed to place participants in one of four mutually exclusive categories for Stage of Change (Precontemplation, Contemplation, Preparation, and Action/Maintenance). Participants who reported finishing the 3-shot vaccine series were categorized in the Action/Maintenance stage. Participants who were planning to start the vaccination series within the next 30 days (or complete within the next 6 months) were categorized in the Preparation stage. Individuals who planned 
on starting the vaccination within the next six months were categorized in the Contemplation stage, and those who had no intention of starting or finishing the vaccine series were classified in the Precontemplation stage. Individuals in the Precontemplation stage were asked an open-ended follow-up question regarding why they did not plan to start or complete the HPV vaccine series. Individuals in the Action/Maintenance stage were asked who recommended the HPV vaccine. Response options included Mother, Father, Yourself, Healthcare Provider/ Doctor, Other (Open-Ended).

\subsubsection{Decisional Balance}

The Decisional Balance scale consists of eight items, four to represent the pros (e.g., protecting myself from HPV would make me feel good) and four items to represent the cons (e.g., it would be embarrassing to talk to my parents or doctor about getting vaccinated) of getting the HPV vaccine. Participants were asked to rate how important each item is in their decision of whether to get the vaccine. Response options were on a 5-point scale ranging from 1 "Not important at all" to 5 "Extremely important".

\subsubsection{Self-Efficacy}

The Self-efficacy scale consists of six items aimed at measuring participants' confidence in their ability to get the vaccine in situations that may prove challenging (e.g., when it is inconvenient). Responses were made on a 5-point scale, ranging from 1 "Not at all confident" to 5 "Extremely confident".

\subsection{Analysis}

An iterative set of analyses was conducted utilizing structural equation measurement modeling. The aims of these analyses were to: 1) provide estimates of the factor loadings and 2) estimate internal consistency for each component using Cronbach's alpha. Item selection was an iterative process, in which items with poor loadings $(<0.40)$ were removed, and analyses were repeated. Final item selection was also determined on the basis of item clarity, lack of redundancy, and conceptual breadth. Once the final items were chosen, multiple measurement models were compared also using structural equation modeling.

In order to determine the model of best fit, four fit indices were used: the likelihood ratio chi-square statistic, goodness of fit index (GFI), the comparative fit index (CFI), and the average absolute standardized residual statistic (AASR). Traditionally, values of $0.80-0.89$ on the GFI and CFI indicate adequate to marginal fit, while values of 0.90 and above indicate good to excellent fit. For the AASR, values below 0.06 indicate excellent fit. More conservative criteria state that an acceptable GFI and CFI should be at least 0.90 while 0.95 and above indicate excellent fit. Factor loadings were assessed and retained above the adequate value of 0.40 .

The TTM hypothesizes that individuals in different Stages of Change will differ significantly on their scores for the Processes of Change subscales [22]. Multivariate Analysis of Variance (MANOVA) tests were conducted on all POC variables by Stage of Change. In order to facilitate comparison in the magnitude of differences in scale scores among the different subscales and between the results of this study and previous studies examining TTM scales, raw scores were converted to T-scores $($ Mean $=50$, standard deviation $[\mathrm{SD}]=10)$. Correlations were examined to determine the relationship between each POC subscale and other TTM variables, including pros, cons, and Self-efficacy.

\section{RESULTS}

\subsection{Initial Item Development and Refinement}

Literature reviews and focus groups were successful in conceptualizing and developing a total of 77 items reflecting the 10 POC as they related to HPV vaccination among women. Items were further refined and clarified during cognitive interviews with participants.

\subsection{Descriptive Data}

Descriptive data gathered with reference to additional motivational influences related to HPV vaccination revealed that among those who were vaccinated (in the Action/Maintenance Stage) 63\% reported that the vaccine was recommended to them by a doctor or other health care provider, $28 \%$ by their mother, $6 \%$ selfrecommended, $1 \%$ by their father, and $<1 \%$ by their high school or college. Participants who were not intending to start or finish the vaccine in the next six months gave a variety of reasons as to why they were not planning on receiving the vaccine. The largest proportion of students indicated fear of risks or side effects $(24 \%)$. Many individuals $(14.6 \%)$ felt they did not have adequate knowledge or were undecided about vaccination Additional reasons included a lack of perceived need or personal risk (14.6\%), lack of time/motivation (11.5\%), believing that the vaccine was too new and insufficient research had been conducted $(11.5 \%)$, moral/personal reasons $(8.3 \%)$, being told not to get the shot by a parent or doctor $(6.3 \%)$, logistical barriers such as cost/access $(5.2 \%)$, and fear of shots $(3.1 \%)$.

\section{Measure Development}

Seventy-seven items were included in the confirmatory structural equation modeling analysis for this measure. Diagnostic indicators provided by the analysis were 
used to detect poorly functioning items. Four items with low loadings $(<0.40)$ on their respective factors were deleted. With these items removed the modeling was repeated and further item deletions were made based on item loading, item complexity, and breadth of construct. These procedures ultimately reduced the number of items from 77 to 40 (4 items per process). Scale means and standard deviations can be seen in Table 1.

Two models were tested: 1) null model (suggesting no latent factors and used as a comparative model) and 2) ten correlated factor model. The ten-factor correlated model demonstrated the best fit to the data, $\chi^{2}(695)=$ 2185.48, $\mathrm{p}<0.001$; $\mathrm{CFI}=0.87$, GFI $=0.74$ and AASR $=$ 0.043. Standardized factor loadings for each item are displayed in Figure 1. The internal consistencies were good, with Cronbach's alphas ranging from 0.76 to 0.92 .

\subsection{External Validation}

The results of the MANOVA examining scores on the ten POC across the Stages of Change were F $(30,960)=$ 4.72, $\mathrm{p}<0.001, \eta^{2}=0.13$. Follow-up ANOVAs revealed that each of the POC subscales was significantly associated with Stages of Change ( $p$ value's $<0.001$ ), with the exception of Dramatic Relief $(p=0.09)$. Inspection of the POC means across Stage of Change using follow-up Tukey tests revealed that individuals in the Precontemplation stage used all POC less than individuals in all other stages ( $p$ value's $<0.05$ ) (see Figures 2 and 3 ). Effect sizes computed for change in POC from Precontemplation to Contemplation ranged from $\mathrm{d}=0.38$ to $\mathrm{d}=$ 0.75 . These are medium to large in magnitude [33].

Mean differences across the later Stages of Change (e.g. Contemplation to Preparation) were not significant. Despite null findings, effects sizes observed for change in Social Liberation $(\mathrm{d}=0.31)$ and Stimulus Control $(\mathrm{d}=$ 0.30) from Contemplation to Preparation, do not rule out the possibility of clinically meaningful change.

The correlations among the POC subscales (experiential and behavioral), Decisional Balance, and Self-efficacy were examined. As can be seen in Table 2, the experiential and behavioral POC were strongly positively correlated with one another and moderately correlated

Table 2. Correlations between processes of change and other TTM constructs.

\begin{tabular}{lcccc}
\hline & $\begin{array}{c}\text { Behavioral } \\
\text { Processes }\end{array}$ & Pros & Cons & Self-Efficacy \\
\hline Experiential Processes & $0.903^{* *}$ & $0.467^{* *}$ & 0.064 & $0.253^{* *}$ \\
Behavioral Processes & -- & $0.398^{* *}$ & 0.044 & $0.279^{* *}$ \\
Pros & & -- & 0.016 & $0.276^{* *}$ \\
Cons & & & -- & -0.022 \\
Self-Efficacy & & & & -- \\
${ }^{* *}{ }_{p}<0.01$ level (2-tailed). & & & &
\end{tabular}

with Pros and Self-efficacy. Cons of seeking the vaccine were not correlated any of the other constructs for HPV vaccination.

\section{DISCUSSION}

The primary objective of this study was to develop a reliable and valid measure of the Processes of Change applied to HPV vaccination among young, adult, college-attending women. Results indicate that the POC measure is reliable and has a stable factor structure. The hypothesized correlated ten-factor structure was supported.

Similar to previous TTM research, our findings indicate that the POC were used least by individuals in the Precontemplation stage. This is consistent with past research and theory [34] indicating that Precontemplators traditionally score lowest on the majority of POC because they are least ready to change their thoughts and actions regarding a given behavior [19,21]. The steepest increase in use of all POC occurred between the Precontemplation and Contemplation stages. The observed effect sizes for these increases were medium to large in magnitude. These findings coincide with research indicating that across health behaviors a large proportion of between stage variance is accounted for by the difference between Precontemplation and all other stages combined (typically, 70\% for experiential POC and 50\% for behavioral POC) [23]. The early and parallel increase in experiential and behavioral POC suggests that for HPV vaccination cognitive and affective experiences coincide with strategic use of personal, social, and environmental resources to promote behavior change.

Clinically, this research can be used to help develop TTM tailored interventions by identifying POC that are emphasized the most or least at particular Stages of Change. While the patterns did not reach statistical significance, Dramatic Relief, was the process emphasized most in Precontemplation but the least in Action/Maintenance. Self-reevaluation, was emphasized the least in Precontemplation but the most in Preparation. In terms of behavioral POC, Stimulus Control and Reinforcement Management, were emphasized least in Precontemplation but most in Action/Maintenance indicating the need for women in later stages to receive feedback on how to manage stimuli and environmental contingences to complete the vaccine series. Additional research using a larger sample is needed to confirm these findings.

This study also reported correlations between POC and other TTM constructs for which relevant published comparisons are unavailable. Our findings indicated that the experiential and behavioral POC were positively correlated with pros and Self-efficacy. These positive correlations are consistent with TTM theory, which in- 

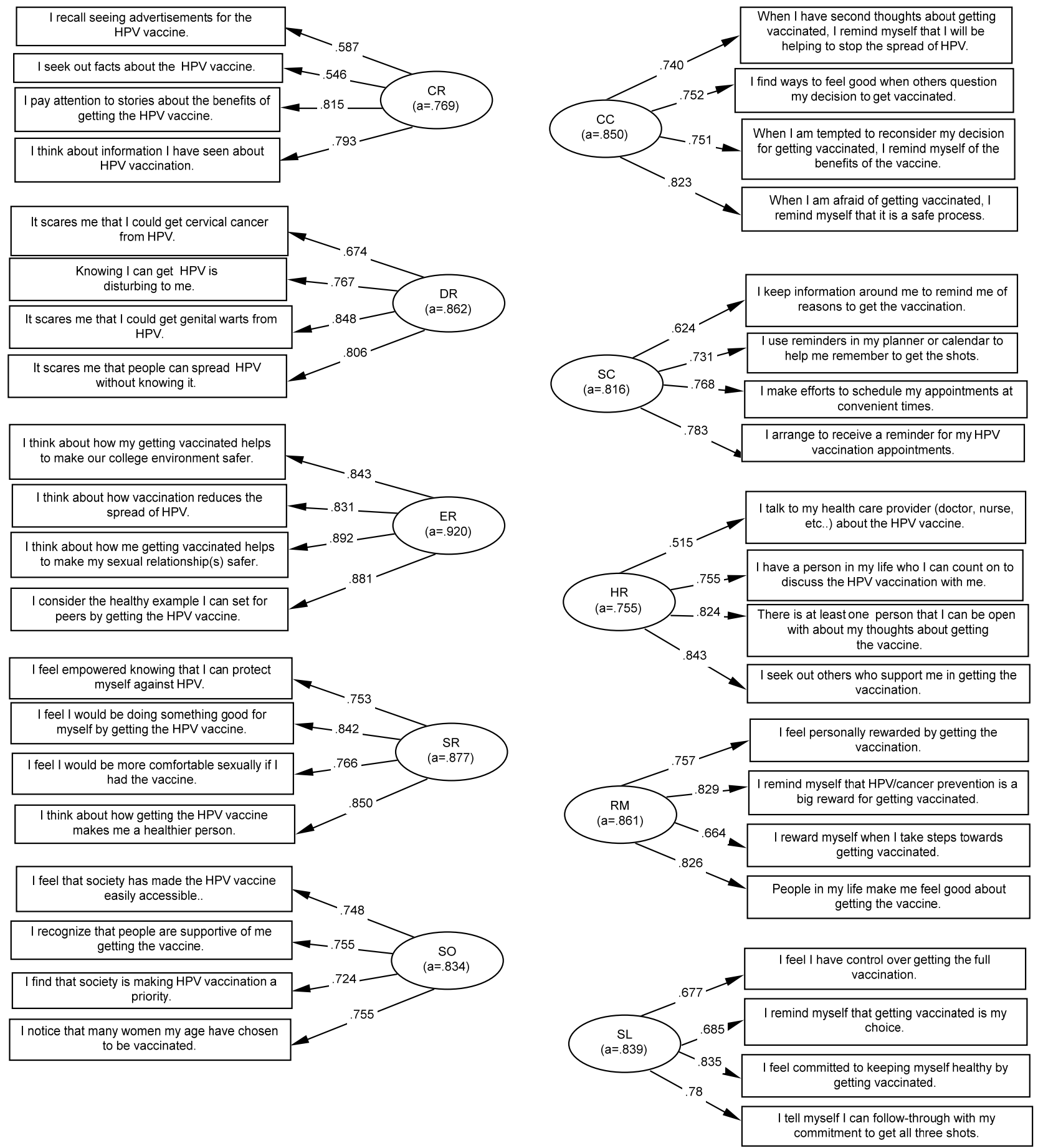

Figure 1. HPV vaccine acquisition processes of change structural mode. $\mathrm{CR}=$ Consciousness Raising, $\mathrm{DR}=\mathrm{Dramatic}$ Relief, $\mathrm{ER}=$ Environmental Reevaluation, SR = Self Reevaluation, $\mathrm{SO}=$ Social Liberation, $\mathrm{CC}=$ Counter Conditioning, $\mathrm{SC}=\mathrm{Stimulus}$ Control, $\mathrm{HR}=$ Helping Relationships, $\mathrm{RM}=$ Reinforcement Management, $\mathrm{SL}=$ Self Liberation.

dicates that a greater number and/or broader range of experiential and behavioral mechanisms are utilized by individuals in later Stages of Change when pros and Selfefficacy are also increasing. 


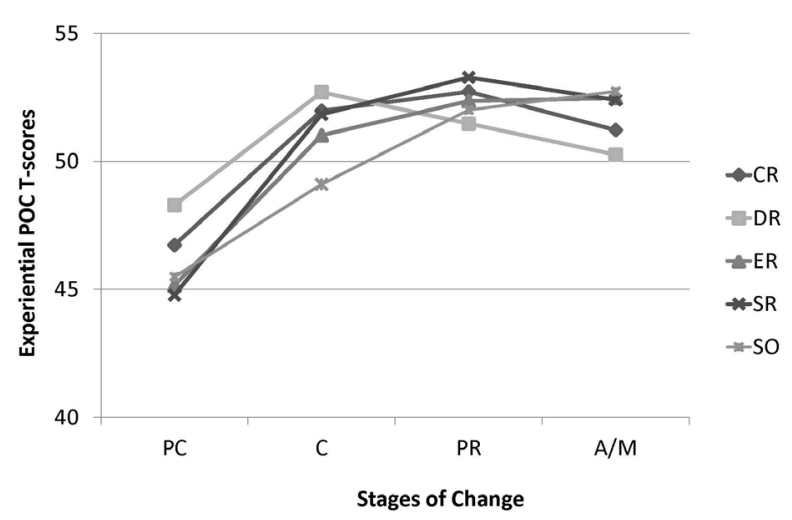

Figure 2. Experiential processes of change X stage of change.

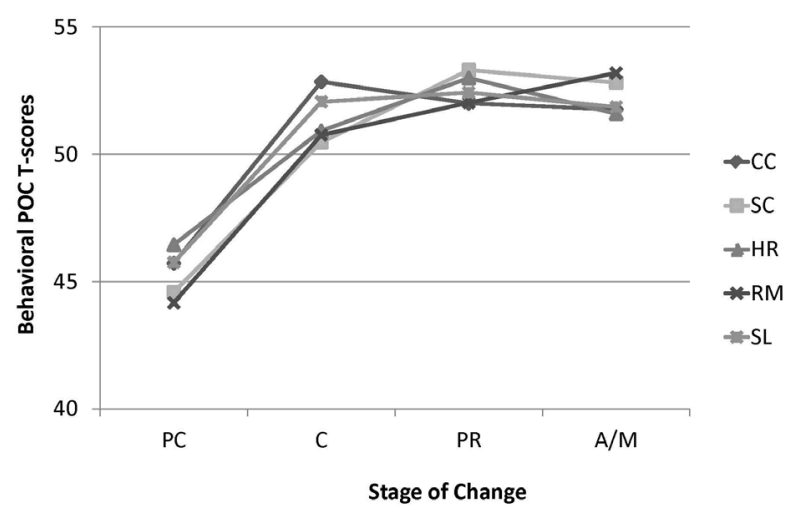

Figure 3. Behavioral processes of change $X$ stage of change. $\mathrm{PC}=$ Precontemplation, $\mathrm{C}=$ Contemplation, $\mathrm{PR}=$ Preparation, $\mathrm{A} / \mathrm{M}=$ Action/Maintenance $\mathrm{CR}=$ Consciousness Raising, $\mathrm{DR}$ $=$ Dramatic Relief, ER $=$ Environmental Reeavaluation, $\mathrm{SR}=$ Self Reevaluation, $\mathrm{SO}=$ Social Liberation, $\mathrm{CC}=$ Counter Conditioning, $\mathrm{SC}=$ Stimulus Control, $\mathrm{HR}=$ Helping Relationships, $\mathrm{RM}=$ Reinforcement Mangagement, $\mathrm{SL}=$ Self Liberation.

Based on these correlations, the experiential POC accounted for $21.8 \%$ of variance in pros but less than $7 \%$ of Self-efficacy. This finding indicates the decision to receive the HPV vaccination may emphasize cognitive processes and perceived advantages of vaccination, rather than confidence in one's ability to carry out a behavior. The finding that $\mathrm{POC}$ is related to pros but not cons suggests that future interventions' emphasis should perhaps be placed on the POC that have the highest correlations with the Pros.

Limitations of this study include the use of a single sample of predominantly white college students residing in the Northeastern United States. Although results of the current research indicate adequate scale reliability and factor stability, further validation is needed among a more diverse sample of young adult women in terms of geography, education, race, and ethnicity. Replication of these findings across diverse samples will provide further evidence of internal and external validity.

Our findings underscore the need for HPV vaccination interventions for women in the earliest Stages of Change when POC need to increase the most. Over $63 \%$ of unvaccinated women in this study were in Precontemplation Stage, and 9 out of 10 POC increased significantly between Precontemplation and Contemplation. TTMtailored interventions should focus on increasing the use of all POC among individuals in the Precontemplation Stage, and maintaining the use of POC until vaccination is complete. This can be done strategically through interventions that use tailoring to accelerate an individual's progress through the Stages of Change [35]. The POC measure validated in this study offers 40 items that could provide innovative behavioral and experiential tactics for producing behavior change. Another direction for intervention efforts is to utilize health care providers or clinics to deliver change-related messages. In this study the most common source cited for vaccination recommendation was health care providers. The most common reason not to get vaccinated was fear of vaccine-related risks and side-effects.

The current research in combination with several other published reports on TTM measurement development for HPV vaccination [32,36] can provide a foundation for developing a TTM-tailored intervention to increase HPV vaccination among young adult women. Due to low rates of vaccination among this population, the need for empirically-based, easily disseminated interventions is clear. The current study represents a first step in developing such an intervention and provides initial guidelines for applying POC across Stage of Change.

\section{REFERENCES}

[1] Centers for Disease Control and Prevention (2008) Genital HPV infection-Fact sheet. http://www.cdc.gov/std/hpv/stdfact-hpv.htm

[2] Koutsky, L. (1997) Epidemiology of genital human papillomavirus infection. The American Journal of Medicine, 102, 3-8. doi:10.1016/S0002-9343(97)00177-0

[3] Myers, E.R., McCrory, D.C., Nanda, K., Bastian, L. and Matchar, D.B. (2000) Mathematical model for the natural history of human papillomavirus infection and cervical carcinogenesis. American Journal of Epidemiology, 151, 1158-1171. doi:10.1093/oxfordjournals.aje.a010166

[4] Baseman, J.G. and Koutsky, L.A. (2005) The epidemiology of human papillomavirus infections. Journal of Clinical Virology, 32S, S16-S24. doi:10.1016/j.jcv.2004.12.008

[5] Dunne, E.F., Unger, E.R., Sternberg, M., McQuillan, G., Swan, D.C., Patel, S.S., et al. (2007) Prevalence of HPV infection among females in the United States. Journal of the American Medical Association, 297, 813-819. doi:10.1001/jama.297.8.813

[6] Trottier, H. and Franco, E.L. (2006) The epidemiology of 
genital human papillomavirus infection. Vaccine, 24, 4-15. doi:10.1016/j.vaccine.2005.09.054

[7] Winer, R.L., Hughes, J.P., Feng, Q., O’Reilly, S., Kiviat, N.B., Holmes, K.K., et al. (2006) Condom use and the risk of genital human papillomavirus infection in young women. The New England Journal of Medicine, 354, 2645-2654. doi:10.1056/NEJMoa053284

[8] Ho, G.Y., Bierman, R., Beardsley, L., Chang, C.J. and Burk, R.D. (1998) Natural history of cervicovaginal papillomavirus infection in young women. The New England Journal of Medicine, 338, 423-428. doi:10.1056/NEJM199802123380703

[9] The Future II Study Group (2007) Quadrivalent vaccine against human papillomavirus to prevent high-grade cervical lesions. The New England Journal of Medicine, 356, 1915-1927. doi:10.1056/NEJMoa061741

[10] Markowitz, L.E., Dunne, E.F., Saraiya, M., Lawson, H.W., Chesson, H. and Unger, E.R. (2007) Quadrivalent human papillomavirus vaccine: Recommendations of the advisorty committee on iimmunization practices (ACIP). Morbidity and Mortality Weekly Report, 56, 1-24. doi:10.1016/i.vaccine.2008.01.013

[11] Harper, D.M. and Paavonen, J. (2008) Age for HPV vaccination. Vaccine, 26, A7-A18.

[12] Dorrell, C., Stokley, S., Yankey, D., Cohn, A. and Markowitz, L. (2010) National, state, and local area vaccination coverage among adolescents aged 13-17 years-United States, 2009. Morbidity and Mortality Weekly Report, 59, 1018-1023.

[13] Greby, S., Lu, P., Euler, G., Williams, W.W. and Singleton, J.A. (2009) Adult vaccination coverage. http://www.cdc.gov/vaccines/stats-surv/nhis/2009-nhis.ht $\mathrm{m}$

[14] Hall, K.L. and Rossi, J.S. (2008) Meta-analytic examination of the strong and weak principles across 48 health behaviors. Preventive Medicine, 46, 266-274. doi:10.1016/i.ypmed.2007.11.006

[15] DiClemente, C.C., Prochaska, J.O., Fairhurst, S.K., Velicer, W.F., Velasquez, M.M. and Rossi, J.S. (1991) The process of smoking cessation: An analysis of precontemplation, contemplation, and preparation stages of change. Journal of Consulting and Clinical Psychology, 59, 295304. doi:10.1037/0022-006X.59.2.295

[16] Prochaska, J.O. and DiClemente, C.C. (1983) Stages and processes of self-change of smoking: Toward integrative model of change. Journal of Consulting and Clinical Psychology, 51, 390-395. doi:10.1037/0022-006X.51.3.390

[17] Velicer, W.F., DiClemente, C.C., Prochaska, J.O. and Brandenburg, N. (1985) Decisional balance measure for assessing and predicting smoking status. Journal of Personality and Social Psychology, 48, 1279-1289. doi:10.1037/0022-3514.48.5.1279

[18] Bandura, A. (1977) Self-efficacy: Toward a unifying theory of behavioral change. Psychological Review, 84, 191215. doi:10.1037/0033-295X.84.2.191

[19] DiClemente, C.C., Prochaska, J.O. and Gibertini, M. (1985) Self-efficacy and the stages of self-change of smoking. Cognitive Therapy and Research, 9, 181-200.

\section{doi:10.1007/BF01204849}

[20] Velicer, W.F., Diclemente, C.C., Rossi, J.S. and Prochaska, J.O. (1990) Relapse situation and self-efficacy: An integrative model. Addictive Behaviors, 15, 271-283. doi:10.1016/0306-4603(90)90070-E

[21] DiClemente, C.C. and Prochaska, J.O. (1985) Processes and stages of self-change: Coping and competence in smoking behavior change. In: Shiffman, S. and Willis, T.A., Eds., Coping and Substance Use. Academic Press, New York, 319-343.

[22] Prochaska, J.O., Velicer, W.F., DiClemente, C.C. and Fava, J. (1988) Measuring processes of change: Applications to the cessation of smoking. Journal of Consulting and Clinical Psychology, 56, 520-528. doi:10.1037/0022-006X.56.4.520

[23] Rosen, C.S. (2000) Is the sequencing of change processes by stage consistent across health problems? A meta-analysis. Health Psychology, 19, 593-604. doi:10.1037/0278-6133.19.6.593

[24] Hall, K.L., Robbins, M.L., Paiva, A., Knott, J.E., Harris, L. and Mattice, B. (2007) Donation intentions among African American college students: Decisional balance and self-efficacy measures. Journal of Behavioral Medicine, 30, 483-495. doi:10.1007/s10865-007-9121-8

[25] Robbins, M.L., Levesque, D.A., Redding, C.A., Johnson, J.L., Prochaska, J.O., Rohr, M.S., et al. (2001) Assessing family members' motivational readiness and decision making for consenting to cadaveric organ donation. Journal of Health Psychology, 6, 523-535. doi:10.1177/135910530100600506

[26] Jackson, D.N. (1970) A sequential approach for personality scale development. Academic Press, New York.

[27] Jackson, D.N. (1971) The dynamics of structured personality tests. Psychological Review, 78, 229-248. doi: $10.1037 / \mathrm{h} 0030852$

[28] Noar, S.M. (2003) The role of structural equation modeling in scale development. Structural Equation Modeling, 10, 622-647. doi:10.1207/S15328007SEM1004 8

[29] Nigg, C.R., Norman, G.H., Rossi, J.S. and Benisovich, S.V. (1999) Processes of exercise behavior change: Redeveloping the scale. Annals of Behaivoral Medicine, 21, S79.

[30] Freyer, J., Bott, K., Riedel, J., Wedler, B., Meyer, C., Rumpf, H.J., et al. (2006) Psychometric properties of the "processes of change" scale for alcohol misuse and its short form (POC-20). Addictive Behaviors, 31, 821-832. doi:10.1016/j.addbeh.2005.06.007

[31] Amoyal, N.R., Robbins, M.L., Paiva, A.L., Burditt, C., Kessler, D. and Shaz, B.H. (2012) Measuring the processes of change for increasing blood donation in black adults. Transfusion, in Press. doi:10.1111/j.1537-2995.2012.03864.x

[32] Larson, H.E., Blaney, C., Kobayashi, H., Sillice, M., Fernandez, A., Lipschitz, J., et al. (2011) HPV knowledge and stages of change measure for HPV vaccing completion among college women. Society of Behavioral Medicine, Washington DC.

[33] Cohen, J. (1988) Statistical power analysis for the behav- 
ioral sciences. Lawrence Erlbaum, New Jersey.

[34] Anatchkova, M.D., Velicer, W.F. and Prochaska, J.O. (2005) Replication of subtypes for smoking cessation within the contemplation stage of change. Addictive Behaviors, 30, 915-927. doi:10.1016/j.addbeh.2005.08.002

[35] Velicer, W.F., Prochaska, J.O., Bellis, J.M., DiClemente, C.C., Rossi, J.S., Fava, J.L., et al. (1993) An expert sys- tem intervention for smoking cessation. Addictive Behaviors, 18, 269-290. doi:10.1016/S0738-3991(98)00129-3

[36] Lipschitz, J.M., Fernandez, A.C., Larson, H.E., Blaney, C.L., Meier, K.S., Redding, C.A., Prochaska, J.O. and Paiva, A.L. (2013) Validation of decisional balance and self-efficacy measures for HPV vaccination in college women. American Journal of Health Promotion, in Press. 